\title{
Influence of moderate hypothermic circulatory arrest on outcome in patients undergoing elective replacement of thoracic aorta
}

\author{
Mohamed Salem, Christine Friedrich, Alexander Thiem, Mostafa Ahmed Salem, Yasemin Erdal, \\ Thomas Puehler, Rene Rusch, Rouven Berndt, Jochen Cremer, Assad Haneya \\ Department of Cardiovascular Surgery, University of Schleswig-Holstein, Campus Kiel, Germany \\ Contributions: (I) Conception and design: M Salem, A Haneya, T Puehler; (II) Administrative support: M Salem, J Cremer, A Haneya, R Rusch, B \\ Rouvin, T Puehler, A Thiem; (III) Provision of study materials or patients: M Salem, J Cremer, A Haneya, T Puehler; (IV) Collection and assembly \\ of data: MA Salem, Y Erdal; (V) Data analysis and interpretation: M Salem, C Friedrich; (VI) Manuscript writing: All authors; (VII) Final approval of \\ manuscript: All authors. \\ Correspondence to: Mohamed Salem, MD. Department of Cardiovascular Surgery, University of Schleswig-Holstein, Campus Kiel, Arnold-Heller-Str. \\ 3, Hs 18, D-24105 Kiel, Germany. Email: drmohsalem83@hotmail.com; mohamed.salem@uksh.de.
}

Background: The ideal technique of cerebral protection in the surgical operation of the ascending aorta. is currently controversial. The current analysis evaluates the influence of moderate hypothermic circulatory arrest (MHCA) on elective replacement of the ascending aorta.

Methods: The study included 905 consecutive patients between 2001 and 2015, who underwent replacement of ascending aorta in MHCA. Patients were divided according to the postoperative 30-day mortality into survivor und non-survivor group.

Results: The average age was $66.5 \pm 11.1$ in survivors vs. $70.0 \pm 10.5$ years in non-survivors $(\mathrm{P}=0.057)$. The survivor group had a significantly lower Euro-SCORE II than non-survivors $[4.0 \%(2.3,6.6)$ vs. 9.5\% $(4.8,20.9) ; \mathrm{P}<0.001)]$. The incidence of coronary heart disease $(38.0 \%$ vs. $58.3 \% ; \mathrm{P}=0.022)$ and chronic renal failure $(10.0 \%$ vs. $33.3 \%, \mathrm{P}<0.001$ was significantly higher in non-survivors. Intraoperatively, the cardiopulmonary bypass time $[140 \min (112,185)$ vs. $194 \min (164,271) ; \mathrm{P}<0.001]$ and cross-clamping time $[91 \mathrm{~min}(64,124)$ vs.119 $\mathrm{min}(94,157) ; \mathrm{P}<0.001]$ were significantly longer in non-survivors. However, the MHCA time was similar in both groups with statistical significance $(\mathrm{P}=0.023)$. Postoperatively, reexploration due to bleeding was highly significant in non-survivors $(5.4 \%$ vs. $33.3 \% ; \mathrm{P}<0.001)$ with a higher incidence of stroke $(4.6 \%$ vs. $33.3 \%$; $\mathrm{P}<0.001)$. The duration of mechanical ventilation was significantly shorter in survivors than in non-survivors $[17 \mathrm{~h}(12,26)$ vs. $147 \mathrm{~h}(49,337) ; \mathrm{P}<0.001]$ with a lower incidence of pulmonary infection $(6.0 \% v s .16 .7 \% ; \mathrm{P}=0.023)$. The multivariable logistic regression analysis showed age, female gender, aortic aneurysm, additional CABG, total arch replacement and cardiopulmonary bypass time were independent risk factors for 30-day mortality.

Conclusions: The acceptable morbidity and mortality rates show that MHCA can be considered as a safe technique for cerebral protection in surgical replacement of thoracic aorta.

Keywords: Cardiac surgery; ascending aorta; hypothermic circulatory arrest; 30-day mortality

Submitted Dec 27, 2019. Accepted for publication May 11, 2020.

doi: $10.21037 /$ jtd-19-4166

View this article at: http://dx.doi.org/10.21037/jtd-19-4166 


\section{Introduction}

Replacement of the ascending aorta is undoubtedly considered one of the most strategically challenging endeavours in cardiac surgery, requiring both understanding of cardiovascular physiology as well as neurophysiology (1). Cerebral protection during this procedure is crucial for a successful of ascending aortic surgery (2). Hypothermic circulatory arrest (HCA) is one of the most preferred and successful method to lower the oxygen consumption and avoid brain tissue injury during the surgical replacement of ascending aorta and aortic arch. This is due to its easy and safe application when compared with antegrade und retrograde cerebral perfusion (ACP, RCP) alone, which reported to be associated with various complications and limitations (3).

However, there is still a huge debate in the cardiovascular surgical field regarding the best method of cerebral protection as well as the degree of temperature used during the period of hypothermic circulatory arrest (4-6).

Various studies were done to figure out the relationship between the hypothermic circulatory arrest using profound and deep temperatures (less than $18{ }^{\circ} \mathrm{C}$ ) and the postoperative outcome (7-9). However, the effect of current usage of moderate hypothermic circulatory arrest (MHCA) with selective ACP on the mortality rate and the postoperative outcomes in patients undergoing elective replacement of ascending aorta is not consistently investigated.

In this current study, we share our experience regarding the application of MHCA during the replacement of the ascending aorta on a large scale of patients suffering from aortic calcification or aneurysm. Moreover, the factors leading to high perioperative mortality were analysed and our results were represented in comparison with various studies using other methods of cerebral protection.

\section{Methods}

\section{Patient population}

The current retrospective study included 905 consecutive patients who underwent replacement of the ascending aorta due to aneurysm or calcification using MHCA $\left(24 \pm 2{ }^{\circ} \mathrm{C}\right.$ nasopharyngeal) in our centre from 2001 until 2015, either isolated or combined with other procedures (e.g., coronary artery bypass grafting, valve replacement).

Patients were divided into two groups based on of 30-days mortality: $96 \%$ survived the 30 -days postoperatively, and
4\% died within this period.

Patients with aortic dissection andredo-operations were excluded from this study.

The primary endpoint was 30-day mortality. Secondary endpoints were intraoperative variables, and the postoperative course (e.g., ventilation time, bleeding, acute renal failure, neurologic complications). In the multivariable logistic regression analysis, a combined target between 30-day-mortality, stroke and delirium was carried out.

Data were collected and extracted from the institution's database and from medical records. The study protocol was approved by the local Ethics Committee in Kiel (D417/17) and the necessary individual patient consent was obtained during the hospital stay.

\section{Patient management}

Calcification or aneurysm of the ascending aorta was observed during routine preoperative investigation before other cardiac surgery or during a routine investigation such as echocardiography or coronary angiography. Aortic calcification is defined as any calcification which avoids the cross-clamping of the aorta, where the calcification is either circular or the thickness of the sporadic calcification is more the $4 \mathrm{~mm}$ within the area of cross-clamping, with possibility of plaques separation and risk of stroke. Aneurysmal dilation is when the diameter of the ascending aorta exceeds $50 \mathrm{~mm}$. In some cases, calcifications or aneurysms were firstly intraoperatively detected by inspection and palpation of the aorta. When calcification of the ascending aorta was suspected preoperatively in any of the routine investigation, a non-contrast computed tomography (CTscan) was performed to estimate the exact location of aortic calcification.

All patients were examined for neurological signs and symptoms and any previous history of cerebral insult as well as any medical records from neurologists are collected and documented on the admission sheet.

Intraoperatively, monitoring of brain tissue oxygenation was carried out by near-infrared spectroscopy (NIRS). If any neurological complications occurred postoperatively, the patient was examined from a neurological consultant directly. The results of the assessment were documented in patient records, followed by head and neck computer tomography to estimate the extent of stroke and brain ischemia. In many cases, CT-angiography for the carotid arteries war required. Magnetic resonance imaging (MRI) was requested from the neurologists on a case by case basis. 
Confusion Assessment Method (CAM) was used to measure the degree of Delirium, if present.

\section{Surgical procedure}

All operations were carried out under general anesthesia by senior surgeons. After median sternotomy and pericardiotomy, the aorta is cannulated distally as a preparation for the cardiopulmonary bypass. A transatrial cannulation of the left ventricle via the right upper pulmonary vein was an alternative method for cannulation arterial cannulation in patients with severe calcification of ascending aorta, where the calcification extending till the aortic arch (10). Cannulation of the right atrium with a common two-stage venous cannula was the standard venous drainage. An antegrade and retrograde injection of cold blood cardioplegic solution was used as a standard for myocardial protection in all cases. MHCA was performed with a nasopharyngeal temperature of $24 \pm 2{ }^{\circ} \mathrm{C}$. Continuous $\mathrm{CO}_{2}$ insufflation was used to avoid cardiac air embolism after surgical opening of the aorta.In cases of necessity to replace the aortic arch, or in cases in which the hypothermic circulatory arrest require more than 20 minutes, an antegrade bilateral cerebral perfusion with oxygenated cold blood $\left(18^{\circ} \mathrm{C}\right)$ was introduced into the head and neck vessels through a balloon catheter with a pressure of $50-60 \mathrm{mmHg}$. Near infrared spectroscopy (NIRS) was used to monitor the Brain tissue oxygenation. Residual air in the left ventricle was removed by restarting retrograde perfusion slowly via the venous cannula beside $\mathrm{CO} 2$ insufflation. After suturing the prostheses with the aorta distally and insertion of the arterial limb of the heart and lung machine directly in the implanted graft, CPB should be restarted again after clamping the aortic prothesis proximally. After suturing the proximal anastomosis, a cardiac de-airing was carried out through a small incision in the aortic prosthesis before opening the clamp. Residual air in the left side of the heart was controlled by transoesophageal echocardiography. During the rewarming phase, other procedures such as CABG were performed.

\section{Statistical analysis}

The statistical analysis is performed using the SPSS 18.0 software (SPSS, Chicago, IL, USA). KolmogorowSmirnow test used to assess the normality of continuous variables. Values of normally distributed continuous data are presented as mean \pm standard deviation and compared by unpaired $t$-test, whereas not-normally distributed continuous data were presented as median with range or interquartile range when appropriate and compared by Mann-Whitney U test. Categorical variables are displayed as frequency distributions (n) and simple percentages (\%). The Chi ${ }^{2}$-test or the Fisher's exact test used for the univariate comparison between the groups for categorical variables. The statistical significance was considered when $\mathrm{P} \leq 0.05$. Parameters with significant missing were excluded from the analysis

Logistic regression analysis was used to determine the relative impact on combined 30-day mortality, delirium and stroke presented as odds ratio (OR) with a $95 \%$ confidence interval. The variables included in the regression analysis: Age, female gender, EuroSCORE II, aortic aneurysm, aortic calcification, diabetes mellitus type II, peripheral vascular disease, chronic obstructive pulmonary disease, coronary heart disease, chronic renal insufficiency, additional CABG, total arch replacement, cardiopulmonary bypass time.

\section{Results}

The overall 30-days mortality rate of the study population was $4 \%$. The average age was $66.7 \pm 11.1$ years $(66.5 \pm 11.1$ in survivors vs. $70.0 \pm 10.5$ in non-survivors; $\mathrm{P}=0.057$ (Table 1). The percentage of female gender showed no significant difference between survivors and non-survivors $33.0 \%$ vs. $38.9 \% ; \mathrm{P}=0.474$ ) representing $33.3 \%$ of the total study population. The non-survivors had a significantly higher Euro-SCORE II than the survivors $[9.5 \%(4.8,20.9)$ vs. $4.0 \%(2.3,6.6) ; \mathrm{P}<0.001)]$. Coronary heart disease was significantly more frequent in non-survivors $(58.3 \% \mathrm{vs}$. $38.0 \% ; \mathrm{P}=0.022)$. The incidence of chronic renal failure as well was significantly higher in non-survivors than in survivors $(33.3 \%$ vs. $10.0 \% ; \mathrm{P}<0.001)$ with more frequent renal replacement therapy $(13.9 \%$ vs. $0.6 \% ; \mathrm{P}<0.001)$. Aortic calcification was significantly higher non-survivors than in survivors $(30.6 \%$ vs. $11.7 \% ; \mathrm{P}=0.003)$. Other risk factors showed no significant difference between both groups.

The intraoperative data analysis revealed that isolated replacement of supra-coronary ascending aorta was performed in $55.9 \%$ in survivors and in $61.1 \%$ in nonsurvivors (Table 2). Non-survivors underwent additional CABG more frequently compared to survivors $(47.2 \%$ vs. $23.6 \% ; \mathrm{P}=0.003)$. The cardiopulmonary bypass time [140 min $(112,185)$ vs. $194 \min (164,271)$; $\mathrm{P}<0.001]$, crossclamping time $[91 \mathrm{~min}(64,124)$ vs.119 $\min (94,157)$; 
Table 1 Preoperative data

\begin{tabular}{|c|c|c|c|c|}
\hline & Total $(n=905)$ & $30-d$ survivors $(n=869,96 \%)$ & $30-d$ deceased $(n=36,4 \%)$ & $P$ value \\
\hline Female gender, $\mathrm{n}$ & $301(33.3 \%)$ & $287(33.0 \%)$ & $14(38.9 \%)$ & 0.474 \\
\hline Body mass index, $\mathrm{kg} / \mathrm{m}^{2}$ & $26.5(24.2,29.4)$ & $26.5(24.2,29.4)$ & $26.0(24.2,29.9)$ & 0.762 \\
\hline EuroSCORE II\% & $4.12(2.38,7.13)$ & $4.0(2.3,6.6)$ & $9.5(4.8,20.9)$ & $<0.001$ \\
\hline Aortic aneurysm, $\mathrm{n}$ & $823(90.9 \%)$ & $799(91.9 \%)$ & $24(66.7 \%)$ & $<0.001$ \\
\hline Diameter of aneurysm, $\mathrm{mm}$ & $52(50,57)$ & $52(50,57)$ & $53(48,60)$ & 0.550 \\
\hline Aortic calcification, $n$ & $113(12.5 \%)$ & $102(11.7 \%)$ & $11(30.6 \%)$ & 0.003 \\
\hline Acute myocardial infarction, $n$ & $10(1.1 \%)$ & $9(1.0 \%)$ & $1(2.8 \%)$ & 0.335 \\
\hline Arterial hypertension, $\mathrm{n}$ & $687(75.9 \%)$ & $663(76.3 \%)$ & $24(66.7 \%)$ & 0.231 \\
\hline Atrial fibrillation, $n$ & $163(18.0 \%)$ & $158(18.2 \%)$ & $5(13.9 \%)$ & 0.660 \\
\hline Chronic obstructive pulmonary disease, $\mathrm{n}$ & $104(11.5 \%)$ & $96(11.0 \%)$ & $8(22.9 \%)$ & 0.051 \\
\hline Coronary heart disease, $\mathrm{n}$ & $350(38.8 \%)$ & $329(38.0 \%)$ & $21(58.3 \%)$ & 0.022 \\
\hline Chronic renal insufficiency & $99(11.0 \%)$ & $87(10.0 \%)$ & $12(33.3 \%)$ & $<0.001$ \\
\hline Renal replacement therapy & $10(1.1 \%)$ & $5(0.6 \%)$ & $5(13.9 \%)$ & $<0.001$ \\
\hline
\end{tabular}

$\mathrm{P}<0.001]$ as well as length of surgery [284 min $(201,304)$ vs. 357 min $(271,454) ; \mathrm{P}<0.001]$ were significantly shorter in survivors than non-survivors. The time of MHCA was similar, however, it showed a statistical significance between both groups $[14 \min (12,17)$ in survivors $v s .17 \min (12,22)$ in non-survivors; $\mathrm{P}=0.023$ ]. Direct cannulation of the distal ascending aorta was the most performed cannulation strategy $(80.7 \%$ in survivors vs. $64.3 \%$ in non-survivors; $\mathrm{P}=0.049)$. Non-survivors received significantly more units of packed red blood cells compared to survivors [(6 units (2, 10) vs. 2 units $(0,4) ; \mathrm{P}<0.001)]$.

Postoperative requirements of high doses of catecholamines were significantly higher in non-survivors than survivors $(17.1 \%$ vs. $3.1 \% ; \mathrm{P}=0.001)$, and $20 \%$ of non-survivors required an extracorporal life support system (ECLS) vs. $0.3 \%$ of survivors $(\mathrm{P}<0.001$, Table 3$)$. The amount of blood loss during the first 48 hours postoperative was significantly higher in non-survivors than in survivors $[1,400 \mathrm{~mL}(788,2,613)$ vs. $550 \mathrm{~mL}(400$, 900); $\mathrm{P}<0.001]$. The incidence of re-exploration due to bleeding or cardiac tamponade was expectedly higher in the non-survivors $(33.3 \%$ vs. $5.4 \% ; \mathrm{P}<0.001)$ as well as the length of mechanical ventilation [147 hours $(49,337)$ vs. 17 hours $(12,26) ; \mathrm{P}<0.001]$ and the incidence of new onset of renal dialysis $(32 \%$ vs. $3.7 \%$; $\mathrm{P}<0.001)$. Non-survivors suffered from more strokes than survivors (33.3\% vs. 4.6\%; $\mathrm{P}<0.001)$. The main cause of death was contributed mainly to cardiac and infectious factors. $20 \%$ of non-survivors required an ECLS, 33.3\% were re-thoracotomized due to bleeding and $16.7 \%$ acquired pulmonary infection.

The multivariable logistic regression analysis for the combined endpoint 30-day mortality, postoperative delirium and postoperative stroke showed that age (OR 1.569; $\mathrm{P}<0.001$ ), female gender (OR 0.569; $\mathrm{P}=0.005$ ), aortic aneurysm (OR 0.454; $\mathrm{P}=0.003)$, additional CABG (OR 1.494; $\mathrm{P}=0.040)$, total arch replacement $(\mathrm{OR} 2.849 ; \mathrm{P}=0.010)$ and cardiopulmonary bypass time (OR 1.006; $\mathrm{P}<0.001)$ were independent risk factors for mortality (Table 4).

\section{Discussion}

Cerebral tissue protection and preventing ischemic organ dysfunction are considered as major concerns in successful aortic surgery. Systemic hypothermic circulatory 
Table 2 Intraoperative data

\begin{tabular}{|c|c|c|c|c|}
\hline & Total $(n=905)$ & 30 - $d$ survivors $(n=869,96 \%)$ & $30-d$ deceased $(n=36,4 \%)$ & $P$ value \\
\hline With aortic valve replacement & $462(51.0 \%)$ & $440(50.6 \%)$ & $22(61.1 \%)$ & 0.237 \\
\hline With CABG & $222(24.6 \%)$ & $205(23.6 \%)$ & $17(47.2 \%)$ & 0.003 \\
\hline With partial arch replacement & $203(22.4 \%)$ & $197(22.7 \%)$ & $6(16.7 \%)$ & 0.541 \\
\hline Conduit, $\mathrm{n}$ & $149(16.5 \%)$ & $142(16.3 \%)$ & $7(19.4 \%)$ & 0.646 \\
\hline David operation, $\mathrm{n}$ & $63(7.0 \%)$ & $62(7.1 \%)$ & $1(2.8 \%)$ & 0.506 \\
\hline Length of surgery, min & $250(203,308)$ & $248(201,304)$ & $357(271,454)$ & $<0.001$ \\
\hline Cardiopulmonary bypass time, min & $142(113,187)$ & $140(112,185)$ & $194(164,271)$ & $<0.001$ \\
\hline Temperature, ${ }^{\circ} \mathrm{C}$ & $24 \pm 2$ & $22-26$ & $21-26$ & 0.033 \\
\hline Number of packed red blood cells, units & $2(0,4)$ & $2(0,4)$ & $6(2,10)$ & $<0.001$ \\
\hline Number of platelets concentrate, units & $1(0,1)$ & $1(0,1)$ & $2(1,2)$ & $<0.001$ \\
\hline \multicolumn{5}{|l|}{ Arterial cannulation, $\mathrm{n}$} \\
\hline Ascending aorta & $680(80.2 \%)$ & $662(80.7 \%)$ & $18(64.3 \%)$ & 0.049 \\
\hline Aortic arch & $107(12.6 \%)$ & $103(12.6 \%)$ & $4(14.3 \%)$ & 0.771 \\
\hline Transatrial through the left ventricle & $48(5.7 \%)$ & $43(5.2 \%)$ & $5(17.9 \%)$ & 0.017 \\
\hline Femoral artery & $10(1.2 \%)$ & $9(1.1 \%)$ & $1(3.6 \%)$ & 0.287 \\
\hline
\end{tabular}

arrest reduces the cerebral metabolic consumption and consequently protects cerebral tissue during aortic surgery as well as providing a bloodless surgical field. Various studies were carried out to investigate the impact of hypothermic circulatory arrest on the postoperative outcomes following aortic surgery (11). However, the ideal strategies of circulatory arrest for aortic surgery is still an issue with a huge current debate $(5,12)$.

Deep hypothermic circulatory arrest (DHCA), with core temperatures of $\leq 18{ }^{\circ} \mathrm{C}$ is used frequently to minimize cerebral injury, beside antegrade (ACP) and retrograde (RCP) cerebral perfusion, which are been used during extended periods of HCA ( $\geq 30-45$ minutes) (5-7). Various cardiovascular units have introduced the isolated deep hypothermia as the method of choice for cerebral protection strategy (13-15), whereas other centres prefer DHCA with adjunct ACP as the gold standard for aortic surgery (12). Chau et al. introduced DHCA as a safe and effective method for cerebral protection against ischemic injury during surgery of the aorta and aortic arch, and postulated that it could be better than ACP and RCP in terms of minimizing stroke and mortality rates as well as in preserving neurocognitive functions. Its simple application provides an optimal field of visualization and is suitable for emergency cases, which cannot be offered by either ACP or RCP (3).

The tendency to use a higher degree of temperature like MHCA rather than deep is increasing nowadays (5). Moderate hypothermic circulatory arrest with direct selective ACP is applied traditionally in the study centre with a nasopharyngeal temperature of $24 \pm 2{ }^{\circ} \mathrm{C}$ in patients undergoing elective surgical replacement of the ascending aorta. Our centre is considered one of the few centres, which uses MHCA as standard protection strategy in aortic surgery, representing a relatively homogenous population for analysis. The acceptable morbidity and mortality results encourage us to share our experience in this field. In addition to the represented results, few studies comparing 
Table 3 Postoperative data and outcomes

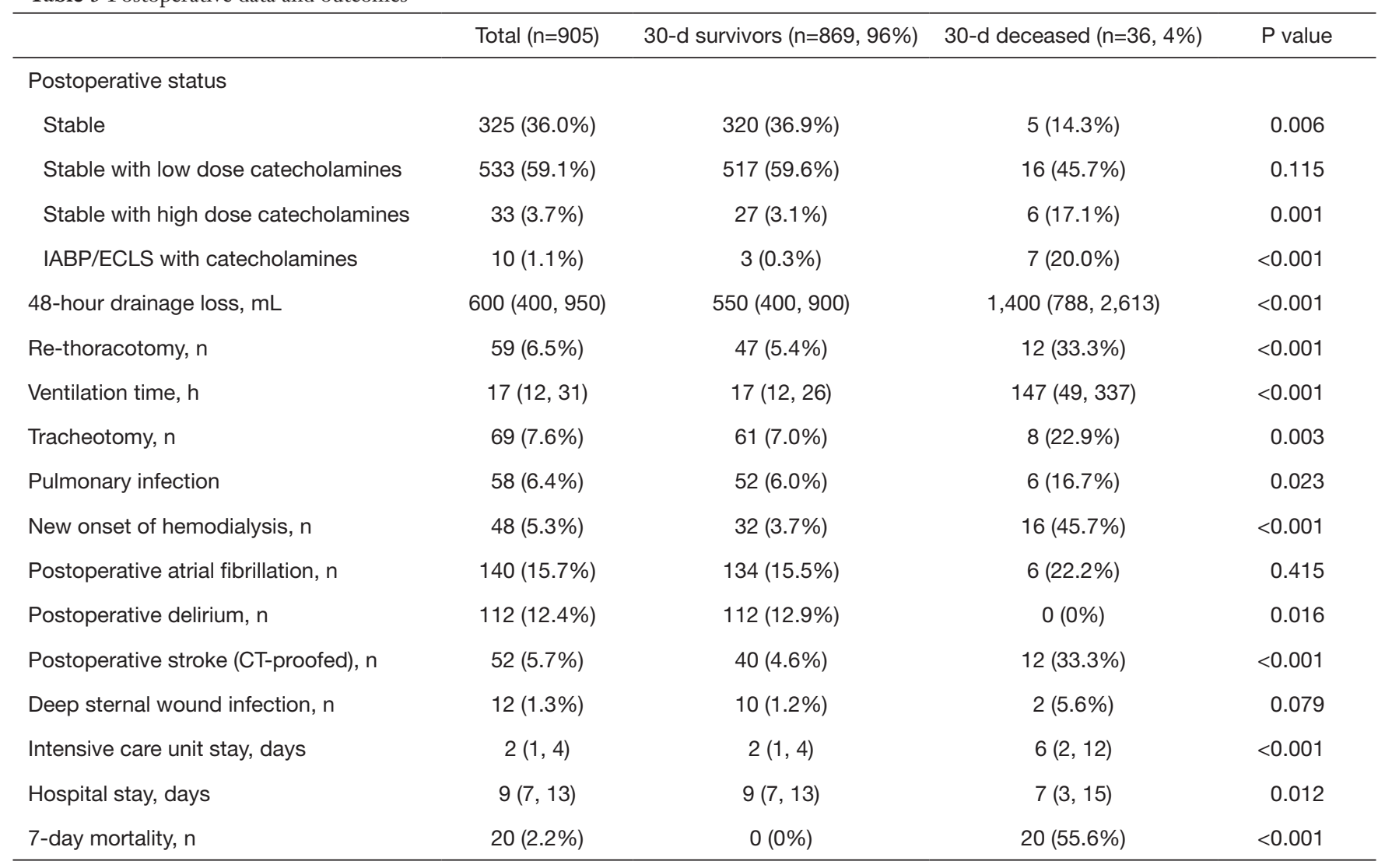

Table 4 Multivariable logistic regression analysis for the combined endpoint 30-day mortality, postoperative delirium and postoperative stroke (back ward selection, Likelihood-ratio)

\begin{tabular}{lccc}
\hline Variable & Odds ratio & $\mathrm{Cl}$ & \multicolumn{1}{c}{$\mathrm{P}$ value } \\
\hline Age & 1.056 & $1.036-1.077$ & 0.001 \\
Female gender & 0.569 & $0.382-0.846$ & 0.005 \\
Aortica neurysm & 0.454 & $0.271-0.760$ & 0.003 \\
Additional CABG & 1.494 & $1.019-2.191$ & 0.040 \\
Total arch replacement & 2.849 & $1.283-6.327$ & $1.003-1.009$ \\
Cardiopulmonary bypass time & 1.006 & $<0.001$ \\
\hline
\end{tabular}

Variables included in the regression analysis: age, female gender, EuroSCORE II, aortic aneurysm, aortic calcification, diabetes mellitus type II, peripheral vascular disease, chronic obstructive pulmonary disease, coronary heart disease, chronic renal insufficiency, additional CABG, total arch replacement, cardiopulmonary bypass time.

different cerebral protection techniques in aortic surgery found out that MHCA with ACP, in comparison with DHCA, showed a significantly lower rate of strokes and postoperative complications $(5,6)$.

During the last years DHCA have been controversially discussed. A review from Ziganshin and coworkers shared their experience in comparing various cerebral protection techniques. The study stated that those alternatives such as isolated ACP and RCP failed to prove better survival and stroke rates compared to DHCA. Moreover, and among a 
large scale of studies between 2007 and 2012, the results of DHCA were very similar, if not better, when compared to other techniques of cerebral protection (16). However, the reduction of postoperative cognitive function and poorer neurological outcomes was considered as a limitation criterion mentioned after the application of DHCA for more than 20 minutes. This limitation necessitates the usage of extra ACP and RCP to reduce the duration of cerebral circulatory arrest $(2,17)$. Controversial, a study from the New York Mount Sinai group showed that DHCA more than 20 minutes (14-40 minutes) did not have an adverse effect on postoperative cognitive function. Moreover, it stated that usage of selective cerebral perfusion during prolonged HCA (39-83 minutes) was one of the significant predictors which reducing memory and language tests (18).

Our results using MHCA as the standard technique in our center were very encouraging. A study from Tian $e t a l$. was among those studies that support our hypothesis in recommending MHCA with ACP in comparison to DHCA. The study showed that the rate of strokes was significantly lower in MHCA with ACP than DHCA, although the study showed no difference in postoperative mortality or renal failure (5). As well, Misfeld and his group confirmed the above finding, reported that MHCA with ACP was associated with fewer incidences of neurologic complications when compared to DHCA with RCP (6).

Our analysis showed also an overall satisfactory result regarding postoperative neurological outcomes $(5.7 \%$ stroke rate), although non-survivors suffered significantly more from postoperative stroke than survivors. As a physiological background to understand the way of cerebral protection in HCA, Ehrlich et al. stated that cerebral metabolic activity and its oxygen consumption can be reduced to $50 \%$ of baseline values at $28{ }^{\circ} \mathrm{C}, 19 \%$ at $18{ }^{\circ} \mathrm{C}$ and down to $11 \%$ at $8{ }^{\circ} \mathrm{C}$ (ultraprofound hypothermia). This study demonstrated that cooling to temperatures below $18{ }^{\circ} \mathrm{C}$ in pigs can achieve greater metabolic suppression although it may be associated with loss of cerebral autoregulation (19). According to Yan et al., hypothermia was categorized into four groups according to physiological findings into mild $\left(34-28{ }^{\circ} \mathrm{C}\right)$, moderate $\left(28-20{ }^{\circ} \mathrm{C}\right)$, deep $\left(20-14{ }^{\circ} \mathrm{C}\right)$ and profound $\left(<14^{\circ} \mathrm{C}\right)(20)$. Cerebral metabolism was described approximately to be depressed by $6-7 \%$ per $1{ }^{\circ} \mathrm{C}$ decline in body temperature. Using an electroencephalograph, it was indicated that the brain electrical activity starts to decrease at mild hypothermia $\left(<33.5^{\circ} \mathrm{C}\right)$ until no further electrical activity can be detected at profound hypothermic temperatures $\left(19-20^{\circ} \mathrm{C}\right)(21)$. Our results indicate that cooling down to the temperature of MHCA $\left(28-20^{\circ} \mathrm{C}\right)$ is sufficient for cerebral tissue protection, especially when it is accompanied by ACP and that there is no need to further cooling in deeper temperatures.

Moreover, we found an overall lower stroke rate compared to other studies applying the same technique of cerebral protection. A recent study from Kamenskaya et al. analyzed the effect of DHCA $\left(18^{\circ} \mathrm{C}\right)$ vs. MHCA $\left(24^{\circ} \mathrm{C}\right)$ combined with antegrade cerebral perfusion (ACP) during the early postoperative period after surgical treatment of chronic dissection of the ascending aorta and the aortic arch. The study stated that moderate hypothermia with ACP demonstrated higher qualities of cerebral protection, resulting in reduced neurologic complications compared to patients who underwent DHCA during surgery. $37.9 \%$ of patients in the DHCA group exhibited neurological complications versus $13.8 \%$ of those in the ACP group $(\mathrm{P}<0.05)(22)$. In comparison with the current results, we proved that usage of MHCA could also achieve satisfactory results regarding the postoperative neurological outcomes with an overall stroke rate of $5.7 \%$ and incidence of delirium of $12.9 \%$.

The overall 30 -day mortality rate was $4.0 \%$. Taking into consideration the high rate of comorbidities in nonsurvivors, we still found that the 30-day mortality rate was satisfactory. A study from Vallabhajosyula et al. comparing the mortality rate in MHCA vs. DHCA in elective aortic transverse hemiarch reconstruction showed a better outcome than our results. The study concluded that MHCA with ACP is considered a safe and efficient circulation management strategy for elective aortic hemiarch replacement with an overall mortality rate of $1 \%$ as well as stroke and transient ischemic attack rate of $0 \%$. Further, the study stated that ACP with the MHCA strategy improved intraoperative outcomes significantly as well as transfusion requirements (23). Those promising results represent a great potential to achieve further better outcomes in the future.

Furthermore, other techniques for cerebral protection as isolated ACP cannot be used in patients with a dissected aortic membrane extending into brachiocephalic or carotid arteries. RCP leads to inadequate neuroprotection due to the inability of a precise estimation of perfusion volume $(24,25)$.

We agreed with those experiences recommending the application of MHCA with direct ACP, due to its simplicity, ease of application and shorter time of re-warming. 
However, we expect that the debate continues and that the community of cardiovascular surgeons will remain divided into various camps, each of them supporting one of those techniques according to their experience and preferences $(14,26,27)$.

\section{Limitations}

The main limitation of this study is its retrospective design. The study is a single-center study and based on a nonrandomized analysis of data.

\section{Conclusions}

Our current analysis reveals that surgical replacement of the thoracic aorta using moderate hypothermic circulatory arrest with selective antegrade cerebral perfusion could be applied easily and safely without increasing the risk of neurological complication or mortality. We encourage the usage of this technique in complex aortic surgery.

\section{Acknowledgments}

Funding: None.

\section{Footnote}

Reporting Checklist: The authors have completed the STROBE Reporting checklist. Available at http://dx.doi. org/10.21037/jtd-19-4166

Data Sharing Statement: Available at http://dx.doi. org/10.21037/jtd-19-4166

Conflicts of Interest: All authors have completed the ICMJE uniform disclosure form (available at http://dx.doi. org/10.21037/jtd-19-4166). The authors have no conflicts of interest to declare.

Ethical Statement: The authors are accountable for all aspects of the work in ensuring that questions related to the accuracy or integrity of any part of the work are appropriately investigated and resolved. This study was conducted in accordance with the Declaration of Helsinki (as revised in 2013). Data were collected and extracted from the institution's database and from medical records. The study protocol was approved by the local Ethics Committee in Kiel (D417/17) and the necessary individual patient consent was obtained during the hospital stay.

Open Access Statement: This is an Open Access article distributed in accordance with the Creative Commons Attribution-NonCommercial-NoDerivs 4.0 International License (CC BY-NC-ND 4.0), which permits the noncommercial replication and distribution of the article with the strict proviso that no changes or edits are made and the original work is properly cited (including links to both the formal publication through the relevant DOI and the license). See: https://creativecommons.org/licenses/by-nc-nd/4.0/.

\section{References}

1. Halushka MK, Angelini A, Bartoloni G, et al. Consensus statement on surgical pathology of the aorta from the Society for Cardiovascular Pathology and the Association for European Cardiovascular Pathology: II. Non inflammatory degenerative diseases - nomenclature and diagnostic criteria. Cardiovasc Pathol 2016;25:247-57.

2. Ergin MA, Uysal S, Reich DL, et al. Temporary neurological dysfunction after deep hypothermic circulatory arrest: a clinical marker of long-term functional deficit. Ann Thorac Surg 1999;67:1887-90; discussion 1891-4.

3. Chau KH, Ziganshin BA, Elefteriades JA. Deep hypothermic circulatory arrest: Real-life suspended animation. Prog Cardiovasc Dis 2013;56:81-91.

4. Friedrich I, Simm A, Kötting J, et al. Cardiac surgery in the elderly patient. Dtsch Arztebl Int 2009;106:416-22.

5. Tian DH, Wan B, Bannon PG, et al. A meta-analysis of deep hypothermic circulatory arrest vs moderate hypothermic circulatory arrest with selective antegrade cerebral perfusion. Ann Cardiothorac Surg 2013;2:148-58.

6. Misfeld M, Leontyev S, Borger MA, et al. What is the best strategy for brain protection in patients undergoing aortic arch surgery? A single center experience of 636 patients. Ann Thorac Surg 2012;93:1502-8.

7. Halkos ME, Kerendi F, Myung R, et al. Selective antegrade cerebral perfusion via right axillary artery cannulation reduces morbidity and mortality after proximal aortic surgery. J Thorac Cardiovasc Surg 2009;138:1081-9.

8. Kazui T, Yamashita K, Washiyama N, et al. Aortic arch replacement using selective cerebral perfusion. Ann Thorac Surg 2007;83:S796-S798. discussion S824-731.

9. Svensson LG, Nadolny EM, Kimmel WA. Multimodal protocol influence on stroke and neurocognitive deficit prevention after ascending/arch aortic operations. Ann 
Thorac Surg 2002;74:2040-6.

10. Schoeneich F, Rahimi A, Eide M, et al. Transatrial left ventricular cannulation for arterial return in CABG with severe aortic calcification. Thorac Cardiovasc Surg 2012;60:60.

11. Luehr M, Bachet J, Mohr FW, Etz CD. Modern temperature management in aortic arch surgery: the dilemma of moderate hypothermia. Eur J Cardiothorac Surg 2014;45:27-39.

12. Englum BR, Andersen ND, Husain AM, et al. Degree of hypothermia in aortic arch surgery-optimal temperature for cerebral and spinal protection: deep hypothermia remains the gold standard in the absence of randomized data. Ann Cardiothorac Surg 2013;2:184-93.

13. Estrera AL, Miller CC, Lee TY, et al. Integrated cerebral perfusion for hypothermic circulatory arrest during transverse aortic arch repairs. Eur J Cardiothorac Surg 2010;38:293-8.

14. Elefteriades JA. What is the best method for brain protection in surgery of the aortic arch? Straight DHCA. Cardiol Clin 2010;28:381-7.

15. Dumfarth J, Ziganshin BA, Tranquilli M, et al. Cerebral protection in aortic arch surgery. Tex Heart Inst J 2013;40:564-5.

16. Immer FF, Lippeck C, Barmettler H, et al. Improvement of quality of life after surgery on the thoracic aorta: effect of antegrade cerebral perfusion and short duration of deep hypothermic circulatory arrest. Circulation 2004; 110:III250-5.

17. Ziganshin BA, Elefteriades JA. Deep hypothermic circulatory arrest. Ann Cardiothorac Surg 2013;2:303-15.

18. Uysal S, Lin HM, Fischer GW, et al. Selective cerebral perfusion for thoracic aortic surgery: association with neurocognitive outcome. J Thorac Cardiovasc Surg

Cite this article as: Salem M, Friedrich C, Thiem A, Salem MA, Erdal Y, Puehler T, Rusch R, Berndt R, Cremer J, Haneya A. Influence of moderate hypothermic circulatory arrest on outcome in patients undergoing elective replacement of thoracic aorta. J Thorac Dis 2020;12(10):5756-5764. doi: 10.21037/ jtd-19-4166
2012;143:1205-12.

19. Ehrlich MP, McCullough JN, Zhang N, et al. Effect of hypothermia on cerebral blood flow and metabolism in the pig. Ann Thorac Surg 2002;73:191-7.

20. Yan TD, Bannon PG, Bavaria J, et al. Consensus on hypothermia in aortic arch surgery. Ann Cardiothorac Surg 2013;2:163-8.

21. Marx JA. Rosen's Emergency Medicine: Concepts and Clinical Practice. 7th edn. Philadelphia: Mosby Elsevier, 2010.

22. Kamenskaya OV, Klinkova AS, Chernyavsky AM, et al. Deep Hypothermic Circulatory Arrest vs. Antegrade Cerebral Perfusion in Cerebral Protection during the Surgical Treatment of Chronic Dissection of the Ascending and Arch Aorta. J Extra Corpor Technol 2017;49:16-25.

23. Vallabhajosyula P, Jassar AS, Menon RS, et al. Moderate Versus Deep Hypothermic Circulatory Arrest for Elective Aortic Transverse Hemiarch Reconstruction. Ann Thorac Surg 99:1511-7.

24. Misfeld M, Mohr FW, Etz CD. Best strategy for cerebral protection in arch surgery: Antegrade selective cerebral perfusion and adequate hypothermia. Ann Cardiothorac Surg 2013;2:331-8.

25. Perreas K, Samanidis G, Thanopoulos A, et al. Antegrade or retrograde cerebral perfusion in ascending aorta and hemiarch surgery? A propensity-matched analysis. Ann Thorac Surg 2016;101:146-52.

26. Bachet $\mathrm{J}$. What is the best method for brain protection in surgery of the aortic arch? Selective antegrade cerebral perfusion. Cardiol Clin 2010;28:389-401.

27. Ueda Y. What is the best method for brain protection in surgery of the aortic arch? Retrograde cerebral perfusion. Cardiol Clin 2010;28:371-9. 